\title{
INDIGO Project: A Simulation Based Approach To Support District Cooling Design And Operation
}

\author{
Andrea Costa $^{1}$, Andrea Bassani ${ }^{1}$, Jesus Febres ${ }^{2}$, Susana López ${ }^{2}$, Saioa Herrero ${ }^{2}$, Miika Rama ${ }^{3}$, \\ Krzysztof Klobut ${ }^{3}$, Yves Stauffer ${ }^{4}$, Rafael E. Carrillo ${ }^{4}$, Gorka Naveran ${ }^{5}$, Marcus Keane ${ }^{6}$, Raymond \\ Sterling ${ }^{6}$ \\ ${ }^{1}$ R2M Solution, Pavia, Italy / ${ }^{2}$ IK4-Tekniker, Eibar, Spain \\ ${ }^{3}$ VTT, Espoo, Finland / ${ }^{4}$ CSEM, Neuchâtel, Switzerland \\ ${ }^{5}$ Giroa Veolia, Zamudio, Spain / ${ }^{6}$ NUI Galway, Galway, Ireland
}

\begin{abstract}
In a district cooling system different types of cooling generation can be combined (e.g., vapour compression chillers, absorption chillers, and free cooling). Controlling such complex systems in an efficient way is challenging: the cooling demand is much more difficult to predict than the heat demand and, as for absorption chillers, heat sources such as the solar energy and the waste heat are not predetermined by the designers.
\end{abstract}

The EU project INDIGO deals with the improvement of District Cooling (DC) systems. Its main goal is the development of a more efficient, intelligent, and cheaper generation of DC systems (Loureiro, 2018; Costa, 2017). The results of INDIGO will include:

- predictive controllers;

- system management algorithms;

- an open-source planning tool.

To validate the results, the consortium is analysing some case studies. The proposed solutions for DC systems will be installed in the Basurto Hospital campus in Bilbao. Different models regarding the buildings and all the relevant components of the DC system are being developed:

1. generation systems;

2. distribution and storage systems;

3. HVAC systems;

4. thermal behaviour of the buildings, considering also internal loads and building use.

The first three parts are being simulated by means of Modelica (Modelica, 2016), an open-source objectoriented modeling language that provides dynamic simulation models for building energy and control systems. The fourth part is being modelled with EnergyPlus (EnergyPlus, 2016). They are going to be integrated through the Functional Mock-up Interface (FMI) for co-simulation (Nouidui, 2014).

The models of certain building envelope elements are validated using experimental measurements (heat flow rates, temperatures, entering solar radiation).

Component models for the air handlers and for the fancoils found in the studied buildings are developed in Modelica. Different kinds of chillers are modelled too. Particular attention is paid to the distribution system, where thermal and hydraulic effects are coupled and thus must be considered jointly.
All the developed models will be validated, both independently and considering the integration, using data acquired at the test-site.

The validated models will be considered as reference for the development of the innovative controllers, of the management strategy, and of the planning tool. The new models developed in Modelica will be part of a District cooling open-source library (DCOL).

\section{Introduction}

This paper presents the role of the energy models in the development of INDIGO, a research project that is funded by the European Union in the context of the Horizon 2020 research and innovation program. The project started in March 2016 and it is going to finish in August 2019. Its main goal is the improvement of the district cooling (DC) systems.

In comparison with the heating systems, the cooling systems present problematic aspects related to the greater difficulty in the prediction of the energy demand. The reason is that the energy demand can change quickly because it is influenced by factors such as the solar radiation and the internal heat loads.

Another problematic issue is that the difference between the supply water temperature and the return water temperature for DC loops is generally around $8^{\circ} \mathrm{C}$, while in district heating loops the difference is usually greater than $40^{\circ} \mathrm{C}$. That causes an increase in the cost of the piping system and of the energy requested for pumping.

The improvement of the DC systems shall be achieved through the development of new tools for the design and for the management of district cooling systems:

- predictive controllers that will be responsible for determining the set-points of the mechanical systems (some of them will include self-learning algorithms), at all levels (generation, distribution, storage, AHUs, and fan-coil units). They will be developed on the basis of "reduced" and validated versions of the energy models (Hoyo Arce, 2017);

- an innovative management strategy, on which the controllers will be based, will consider energetic aspects, environmental aspects, and economical aspects;

- an open-source planning tool for the evaluation of existing systems and for the design of new district cooling systems. It will be based also on the results of simulations; 
- an open library including physical/mathematical models developed in Modelica of the components that compose a DC system that will be called District cooling open-source library (DCOL).

The models regard mainly the real situation of the Basurto Hospital, in Bilbao, which is divided in 20 buildings, among them 9 are mechanically cooled. The results of INDIGO are going to be applied and measured in the plants relative to that facility. The DC system was installed in 2003 and extended in 2011 by Veolia-Giroa. The chilled water is produced by two absorption chillers and by four vapour compression chillers. The system supplies chilled water always at $7^{\circ} \mathrm{C}$ (as setpoint temperature) and it modulates the water flow rate. The absorption chillers are cooled by water loops, one vapour compression chiller is water-cooled while the other three electric chillers are air-cooled (Fig. 1). The hot water, which is used by the absorption chillers and to heat the buildings, is heated by the waste heat of a cogeneration system. That heat can be stored in a water tank. The cogeneration system is activated based on the economic convenience of producing electricity.

In this case the cooling demand is particularly variable because it depends on the number of scheduled surgeries and on the occupancy level as well (Passerini, 2017).

The internal zones are conditioned mainly though Air Handling Units (AHUs) or through fan-coil units. Since the local regulations for hospitals do not permit air recirculation, an important amount of energy is requested for the treatment of the outdoor air.

In the other two pilot cases, located in Barcelona, the models and the INDIGO solutions (controllers and management system) will be tested without a physical installation. They are not considered in this paper.

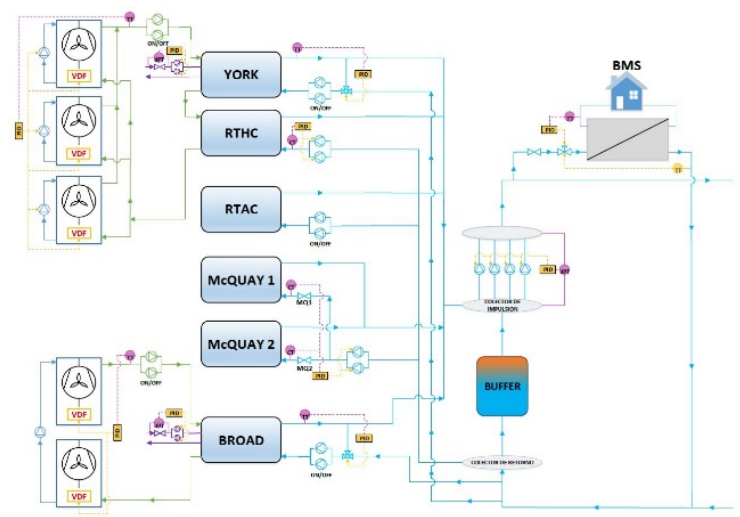

Figure 1: Scheme reporting the situation of the cooling production/distribution plant in the hospital

\section{The integrated detailed modelling}

\section{Functional Mock-up Interface (FMI)}

Different partners of the project consortium are developing different parts of models that regard the buildings and the DC system of the Basurto hospital. The different parts will be integrated, and they are:

1. generation systems;

2. distribution and storage systems;

3. HVAC systems inside the buildings;
4. building geometry, thermal behaviour of the building structures, internal loads, and building use.

5. Learning algorithms, control and optimisation.

6. Planning tool.

The fourth part will be developed in EnergyPlus and will be converted into functional mock-up units (Blochwitz, 2012) that will be then imported and used in a Modelica model that includes the AHUs. The weather data will be integrated in the same functional mock-up unit (FMU) of the building. The FMU will have as input variables latent and sensible heat gains provided by the AHUs to each conditioned thermal zone and as output variable room conditions (zone air temperature and relative humidity) and outdoor air conditions.

The combined Modelica-AHUs with EnergyPlus-FMUs will be then converted into another FMU and used for training an advanced control algorithm to be developed in INDIGO and for the integration with the distributionstorage-generation models, which are being created in Modelica.

The integration of different tools allows the exploitation of their different capabilities. EnergyPlus is a whole building energy simulation software, whose development is funded by the U.S. Department of Energy - Building Technologies Office. It is free, open-source, and crossplatform. In EnergyPlus many physical-mathematical models relative to the building physics (as well as to the HVAC systems) are already available and validated. Modelica is a non-proprietary, object-oriented, equationbased language. The use of a Modelica library (Wetter, 2014) and the development of new models require the use of a Modelica simulation environment (some environments are commercial, a few environments are free). The use of Modelica allows a greater flexibility than EnergyPlus. A similar approach has been applied to water networks control optimisation (Perfido, 2017).

\section{Validation}

The models will be validated, at different levels, using measured data. The quality of the measured data will be checked in order to eliminate the unreliable ones. The validation process will consider statistical test methods, with the definition of an acceptable range of accuracy with respect to the model goal. It will be an iterative process.

The validated models will be then used as a tool for the improvement of the plant and for the development of other tools, such as the controller, the management strategy, the planning tool.

A monitoring campaign has started in summer 2016 and it has been completed in spring 2018. A Building Management System (BMS) is installed and some data used for the validation were already being measured, while other data are being measured or are going to be measured because it was requested by the measurement plan developed for this project.

\section{Generation systems}

The models of the generation system that are being developed are: water cooled vapour compression chillers, 
air cooled vapor compression chillers, absorption chillers, cooling towers, heat exchangers (plates and shell \& tube), and pumps. The development is being carried out in Modelica. The following measurements, with a time step equal to 1 minute, are available:

- cooling energy produced by each chiller (elaboration from water flow rate and temperatures)

- total cooling energy produced by the plant (elaboration from water flow rate and temperatures)

- electric consumption in each chiller

- gas consumption of the cogeneration engines

- supply and return temperature of the hot water loop for each absorption chiller

- supply and return temperature of the heat rejection loops (cooling towers)

- water temperature in the supply and return manifolds

- outdoor temperature.

- Distribution and Storage systems

Outside the building where the generation system is located, there is a buffer tank for cold water that is installed between the return and supply manifolds (its volume is $25 \mathrm{~m} 3$ ). The chilled water temperature is measured at the top and at the bottom of the tank.

The length of the distribution piping is about $2 \mathrm{~km}$ (supply pipes plus return pipes), split in two branches. The DC grid sends chilled water to 9 buildings where substations are installed. The total substations are 11 because in two of the buildings there are two substations. Only in a substation there is a heat exchanger, while in other ones there are hydraulic separators between the DC loop and the loop inside the buildings. In some cases, energy meters are installed in the building side of the substation.

The central pumps are connected to a frequency converter that allows the variation of their speed.

As for the models of valves, pumps and fittings, the relative models available in the Modelica Standard Library are being used. As for the pipes, a new model, based on the "plug-flow" approach, is being developed. The roughness of the pipes, since it influences the hydraulic resistance and it raises the water temperature, the heat losses through the pipes, and the thermal inertia of the distribution system are being considered.

As for the water tanks, phenomena like the thermal energy charging and discharging process, the stratification, and the heat losses are being considered.

\section{HVAC systems}

Several libraries exist in Modelica for modelling and simulation of HVAC systems. The INDIGO team decided to use the Annex60 (Wetter, 2015) Modelica library as a basis for the component models and develop whichever component was not included in the library.

This section deals with the modelling and simulation of the Air Handling Units (AHUs) that serve one of the demonstrator buildings, the Aztarain Block in Basurto Hospital. Aztarain is served by two main AHUs as the one shown in Fig. 2.

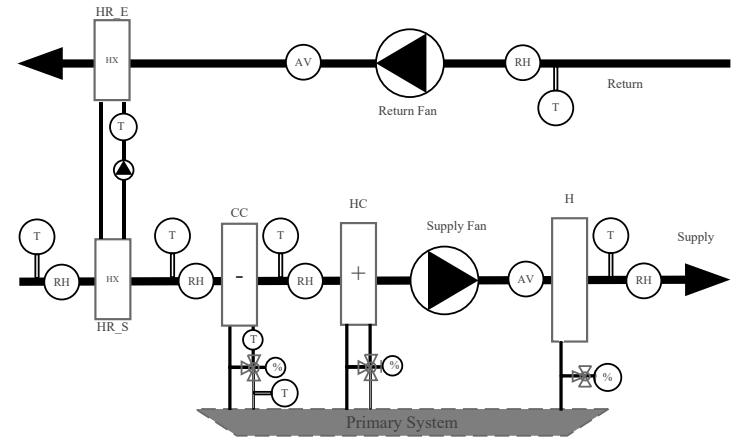

Figure 2: Schematic of Aztarain AHUs

The unit is composed of heat recovery (HR) based on two heat exchangers with a close water circuit as transfer fluid, cooling coil (CC), heating coil (HC), supply and return fans, humidifier $(\mathrm{H})$, valve position $(\%)$ and sensors: temperature $(\mathrm{T})$, relative humidity $(\mathrm{RH})$, air velocity (AV). In the Aztarain building an AHU serves pressure positive rooms for immuno-depressed or critical patients. Another AHU serves all the other areas. For the underground floor the supplied air can be post-heated or post-cooled by water coils installed in local boxes, where the renovation air flow rate is mixed with recirculated air.

The Annex60 library contains models for the fans, the heating coil, and the humidifier. However, a model for the cooling coil is not implemented yet. An initial implementation of the cooling coil model has been made based on the efficiency-NTU method. These models will be validated using real operation data from the facility after the monitoring and instrumentation is upgraded to match the instrumentation shown in Fig. 2. Attention will be focused on the cooling coil given the aim of the INDIGO project to improve operations of district cooling systems. To calibrate and validate the cooling coil models a procedure based on (Febres, 2015; Febres, 2017) has been proposed whereby the full range of operation of the coil is explored at discrete steps. This is done by modulating the cold-water control valve as shown in Fig. 3.

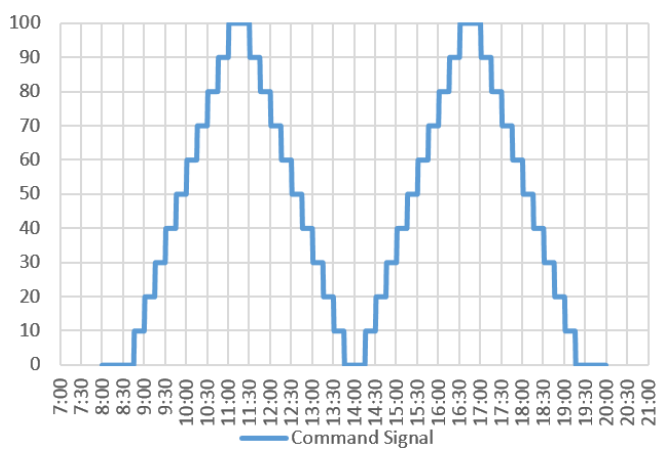

Figure 3: Controlling variable signal

In this validation scenario, the input and output air temperature and relative humidity are monitored at 1minute intervals over the validation period. With this approach, it is possible to characterise the relationship between valve command and output conditions and hence validate the suitability of the model for the specific coil. 
The rest of the components will be validated during normal operations to avoid disrupting the hospital functioning.

\section{Building, internal loads, users}

Some measurements relative to the building have started in summer 2016. They regard the building envelope.

The thermographic camera has been used for detecting irregularities in the building envelope. In this way the best position for the heat flow meter can be evaluated. The heat flow meter was used to measure the heat flow rate through the roof and the external walls of the Aztarain building. During the same period the outdoor and the indoor air temperature, the outdoor and the indoor surface temperature were measured (Fig. 4). The data relative to the solar radiation and to the wind velocity and direction are available through the weather station "C039 - Deusto" of the Basque agency of meteorology ("Agencia vasca de meteorología").

Generally, the measurements made through the heat flow meter are indicative when there is an important difference (at least $10^{\circ} \mathrm{C}$ ) for some consecutive days between the indoor temperature and the outdoor temperature. Normally this happens during the winter season. Nevertheless, in this case the measurements were carried out in summer because the research is interested in modelling the cooling demand and therefore in analysing the behaviour of the structures in hot conditions and when they are stricken by a high solar radiation.

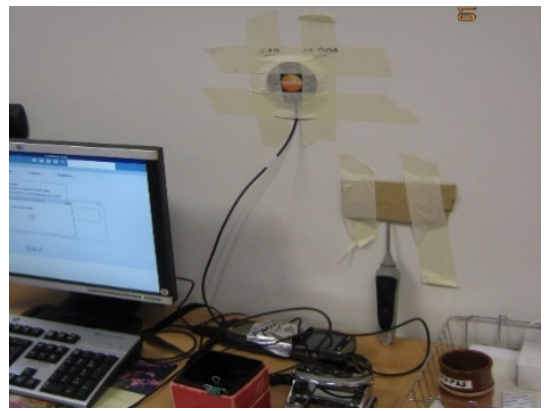

Figure 4: Internal measurement equipment for heat flow rate, surface temperature, and air temperature

The validation of the models of the walls and of the roof is considering: amplitude of peak, time between two peaks, minimum, maximum and mean values, slope and the number of inflection points, attenuation factor relative to the external and the internal oscillations, time delay between external surface temperature and internal surface temperature or internal heat flow rate. The surface emissivity is being evaluated through a thermographic camera: the surface temperature is measured at the same time with a thermographic camera and with a surface thermometer and the emissivity considered by the thermographic camera is adjusted until it measures the same value measured by the surface thermometer.

The surface solar absorptance considered in the model is adjusted in order to have an acceptable agreement between measured and calculated outside surface temperatures. The results obtained with different models of the outdoor convection coefficient are going to be compared with measured data in order to select the most appropriate one for the analysed case.

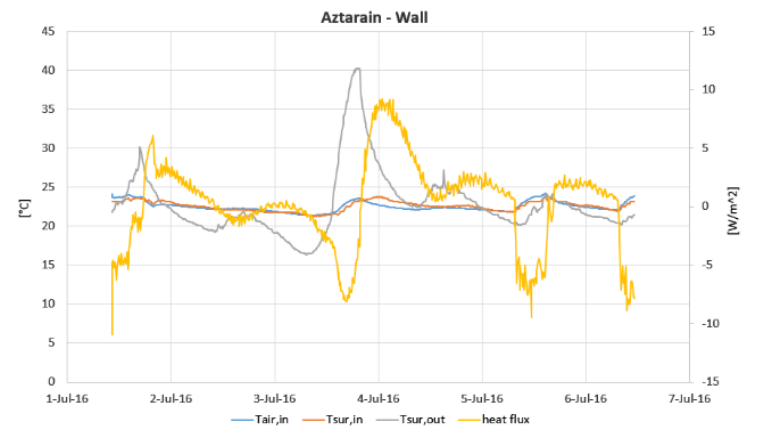

Figure 5: Elaboration of measured data relative to an external wall of Aztarain building

A pyranometer was used with different sky conditions in order to evaluate the ratio between the solar radiation flux density $(\mathrm{W} / \mathrm{m} 2)$ entering through the windows and the external solar radiation on a plane parallel to the window.

As explained above, in the summer of 2016 a measurement campaign was conducted for the validation of the Aztarain building model. The measured data were internal air temperature $\left[{ }^{\circ} \mathrm{C}\right]$, the envelope inside surface temperature $\left[{ }^{\circ} \mathrm{C}\right]$, the envelope outside surface temperature $\left[{ }^{\circ} \mathrm{C}\right]$ and the total heat flow across the envelope [W/m2]. The same measurement campaign was subsequently conducted in 2018 in the months of April and May with the goal to validate the heat flow across the roof of the Aztarain building and the heat flow across the building envelope and the glass surfaces of the buildings Areliza (Bloque quirurgico) and Gurtubay.

Thanks to the measurements, it was possible to obtain the validation of all the selected structures. A very important aspect was the creation of a weather file that allowed us to be able to carry out the simulations by considering the real climatic data of the period considered. The development of the building models that represent geometry, materials, boundary conditions (e.g. ground temperature), air infiltration and internal gains of the building were developed in DesignBuilder that is a building simulation software with which is possible to perform dynamic simulation. Then the models were exported into EnergyPlus and, finally, from EnergyPlus into a Functional Mock-up Unit.

EnergyPlus manages input files in .idf format, which can be edited in the IDF Editor (free available online) or in a text editor. The input data that the building model acquires from the HVAC system model, which is developed in Modelica, and the output data that the building model transfers to the HVAC system model are listed in the .idf file. The weather data are included in an .epw file (EnergyPlus weather file). The information included in the .idf file and that one included in the .epw file are combined in a file that is readable by Modelica, specifically in a .fmu file. The exportation to .fmu is done through a Python script. 


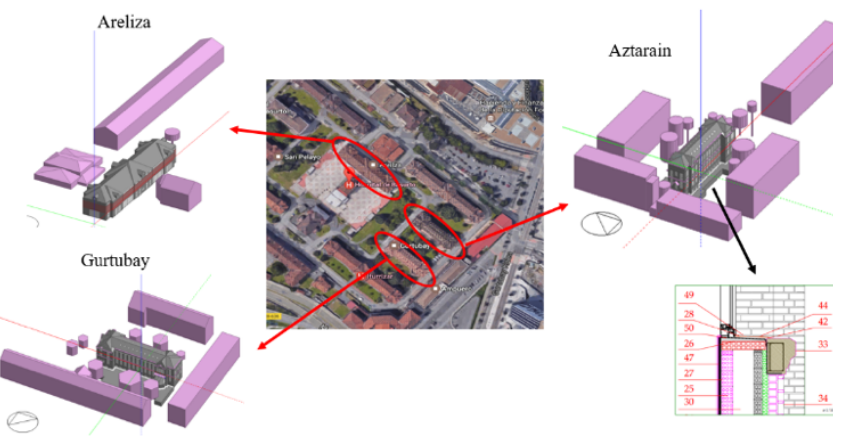

Figure 6: Basurto site and the 3 buildings with detailed models

To validate the model, after examining several validation methods it was considered appropriate to use the RMSE and the RMSEN (Root Mean Square Error Normalized) method, the result of which is the measure of how much the simulated values deviate from the expected value.

$$
R M S E=\sqrt{\left[\frac{\sum_{i=1}^{N}\left(M_{i}-S_{i}\right)^{2}}{N}\right]}
$$

M: measured values

S: values obtained from the simulations

$\mathrm{N}$ : number of acquired data

$$
R M S E_{N}=\left[\frac{R M S E_{\text {period }}}{A M_{\text {oscillation }}}\right] X 100 \%
$$

The RMSEN express the value of the RMSE normalized respect to the amplitude of the oscillation of the data measured.

Greater attention has been paid to minimizing the error concerning the thermal flow that passes through the structures as the latter determines the thermal behavior of the envelope and knowing the heat that must be removed from the AHUs is fundamental from the point of view of the optimization of the cooling system.

In order to obtain a reduction of the difference between the measured data and the results of the simulation, 2 algorithms and 3 parameters to be analyzed were identified. The two algorithms represent the internal and external surface convection of the surfaces (Surface Convection Algorithm:Inside - Surface Convection Algorithm:Outside).

The three parameters are respectively the solar absorption, the emissivity and the density of the materials. For each parameter or algorithm, a sensitivity analysis was performed evaluating the effects due to variation of the model variables on the results so as to identify the values or types of algorithms that in this situation allow us to minimize the RMSE.

The best results are achieved by setting the following parameters in the Energy Plus model:

\footnotetext{
- Convection algorithm: TARP-MoWiTT
}

\section{- $\quad$ Solar Absorption: 0,75}

- $\quad$ Thermal Absorption: 0,8

Results of the validation of the wall of Aztarain building:

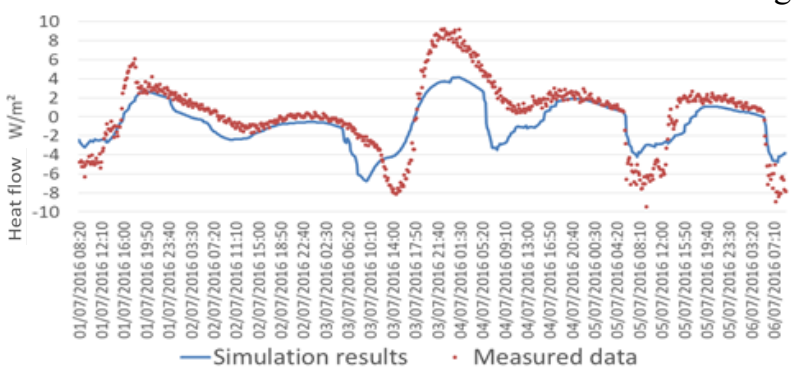

Figure 7: Heat flow across the Aztarain external wall (heat flow vs time)

Table 1: Aztarain building external wall simulation

\begin{tabular}{|c|c|c|c|c|}
\cline { 2 - 5 } & $\begin{array}{c}\text { Internal } \\
\text { temperature } \\
\text { of Zone }\end{array}$ & $\begin{array}{c}\text { Wall inside } \\
\text { surface } \\
\text { temperature }\end{array}$ & $\begin{array}{c}\text { Wall } \\
\text { outside } \\
\text { surface } \\
\text { temperature }\end{array}$ & $\begin{array}{c}\text { Heat flow } \\
\text { rate though } \\
\text { the wall }\end{array}$ \\
\hline RMSE & $0,93^{\circ} \mathrm{C}$ & $0,85^{\circ} \mathrm{C}$ & $2,43^{\circ} \mathrm{C}$ & $2,40 \mathrm{~W} / \mathrm{m} 2$ \\
\hline RMSE $_{\mathrm{N}}$ & $32,42 \%$ & $32,82 \%$ & $10,17 \%$ & $11,87 \%$ \\
\hline
\end{tabular}

Through the validation process, the RMSE value of the Heat Flow has been reduced by $14,52 \%$ from a value of $2,8 \mathrm{~W} / \mathrm{m} 2$ to a value of $2,4 \mathrm{~W} / \mathrm{m} 2$ as can be seen. Moreover, the RMSE value concerning the external surface temperature which initially was equal to $2,99^{\circ} \mathrm{C}$ has been reduced to $18,57 \%$ reaching a value of $2,43^{\circ} \mathrm{C}$.

Given that the main focus of the model is to predict the cooling demand, although the normalized RMSE of internal temperature and wall inside surface temperature are higher than $30 \%$ this was considered as a stopping point at this stage but we are investing on how to decrease this. In relation to the results of the validation of the roof of Aztarain building: the validation of the heat flow that crosses the roof was completed only in 2018 thanks to the new measurement campaign.

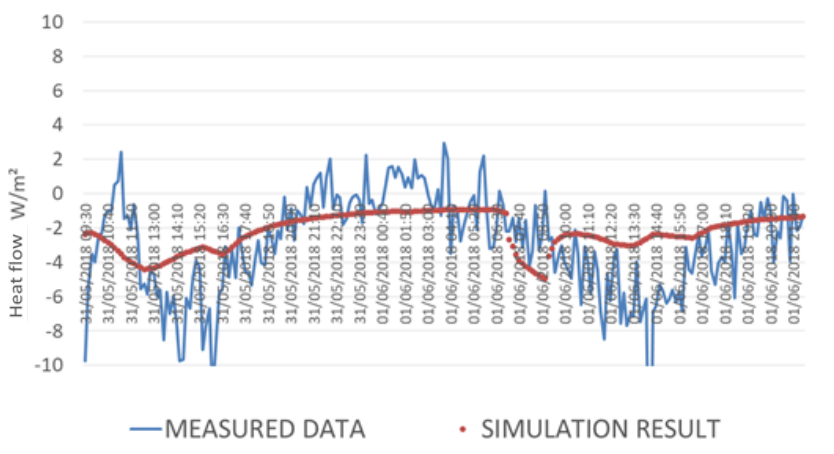

Figure 8: Heat flow across the Aztarain roof (heat flow vs time)

The results obtained on the Areliza and Gurtubay buildings were achieved following the same procedure used for the validation of the Aztarain building. In these two cases the room temperature set-point played an important role since it was not aware of its exact real value.

After having carried out some tests, it was decided to use as a reference of the outside temperatures the 
temperatures measured directly on the site instead of the temperature values taken by the weather stations close to Basurto, given that they obtained better results

The best results on the opaque surface are achieved by setting the following parameters:

- Convection algorithm: TARP-MoWiTT

- Solar Absorption: 0,75

- Thermal Absorption: 0,8

Results obtained studying the heat flow through the external wall of Areliza Building:

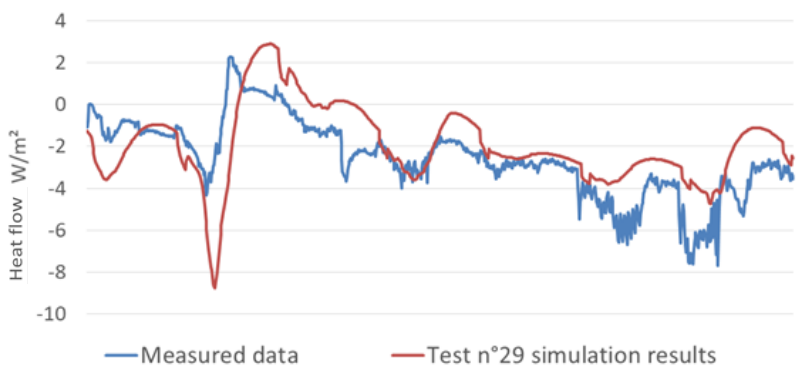

Figure 9: Heat flow across the Areliza external wall (heat flow vs time)

For the glazed surfaces of the Areliza building, in addition to the previously mentioned parameters, the features of glass and gas contained within the window have been studied.

The output of energy plus chosen to study the thermal flow through the glazed surface is:

- Surface Window Net Heat Transfer Rate [W]

(To obtain the value of the $\left[\mathrm{W} / \mathrm{m}^{2} \mathrm{~K}\right]$ this parameter has been divided for the window surface and the difference between the internal temperature of the zone and the external temperature).

80

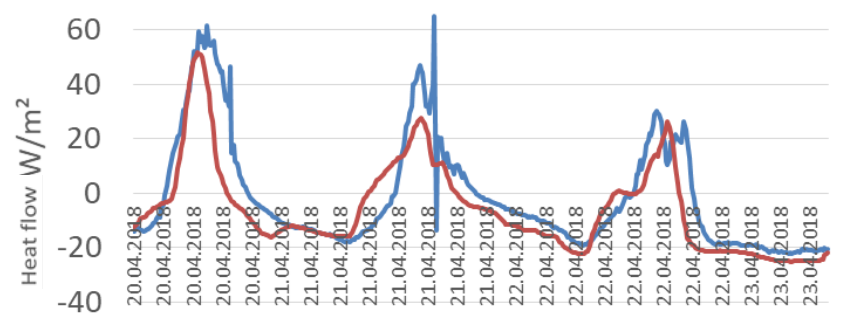

-Measured data -Simulation results

Figure 10: Heat flow across the Aztarain glass surfaces (heat flow vs time)

Also in the case of the study of the glazed surfaces, thanks to an accurate analysis of the factors influencing the heat flow that passes through the glazed surface, good results were obtained in terms of deviation of the results of the simulation respect to the measured data, in fact the value of the RMSEN does not exceed $15 \%$.

Additional measurements that are going to be carried out in order to improve the input accuracy regard mainly the internal loads and the behaviour of the users. They are: internal heat gains (metering of the consumption of medical equipment, communication racks, UPS systems,
IT equipment, and any other relevant equipment), window openings (magnetic sensors), $\mathrm{CO} 2$ concentration.

The correlation between the opening of the windows and other parameters (e.g. $\mathrm{CO}_{2}$ concentration, indoor and outdoor temperatures) will be investigated.

Since the control of the HVAC system is based on the return air temperature, the rooms have been divided in thermal zones gathering all the rooms of a floor that are supplied by the same AHU. For the underground floor of the Aztarain building the division has considered also the distribution of the reheating/recooling boxes.

\section{Learning algorithms, control and optimisation}

Models are a key component of model predictive controllers (MPC) since they must be accurate enough to avoid erroneous control strategies but, at the same time, they need to be fast such that the optimization problem can be solved in real time.

We tested two types of reduced models for the MPC: 1) Physical model and 2) long short-term memory recurrent neural network (LSTM-NN). The physical model uses a simplified physical model for the AHU coupled with a linear auto-regressive model for the room envelope. The coefficients of the auto-regressive model can be updated every week, or every season based on observed data. The LSTM-NN is a purely data-driven model that represents the whole system as an input-output function. The LSTM$\mathrm{NN}$ is trained from simulated data (produced via detailed models described in the previous) using different weather profiles and setpoint strategies to avoid overfitting and achieve a good approximation of the system dynamics. Transfer learning techniques will be used to update the LSTM-NN model with observed data from the test site in such a way that it does not forget the dynamics learnt from the training period.

The MPC developed within INDIGO aims at minimising the energy consumption at building level while maintaining thermal comfort. The cost function used by the proposed MPC is the following:

$$
\begin{gathered}
\min _{x_{t}, x_{r h}} \sum_{k=1}^{H}\left[w_{c}(k) p_{c}(k)+w_{h}(k) p_{h}(k)\right] \\
+\lambda \sum_{k=1}^{H}\left\{w_{t}\left[t_{r}(k)-t_{i}(k)\right]^{2}+w_{r}\left[r h_{r}(k)-r h_{i}(k)\right]^{2}\right\}
\end{gathered}
$$

Where:

$$
\begin{aligned}
& x_{t} \rightarrow \text { supply temperature } \\
& x_{r h} \rightarrow \text { supply rel. humidity } \\
& t_{i} \rightarrow \text { ideal room temperature } \\
& r h_{i} \rightarrow \text { ideal room rel. humidity } \\
& \theta \rightarrow \text { external signals } \\
& p_{c} \rightarrow \text { cooling power } \\
& p_{c} \rightarrow \text { heating power } \\
& \boldsymbol{t}_{r} \rightarrow \text { room temperature } \\
& r h_{r} \rightarrow \text { room rel. humidity }
\end{aligned}
$$

The optimization (control) variables are the supply temperature, $\boldsymbol{x}_{\boldsymbol{t}}$, and the supply relative humidity (RH), $\boldsymbol{x}_{\boldsymbol{r} \boldsymbol{h}}$, setpoints for the AHU. The problem computes the optimal setpoints for a prediction horizon of 24 hours. The objective function has two terms: 1) energy consumption 
and 2) distance to desired comfort level. The regularization weight $\lambda$ is a positive constant that balances the trade-off between energy consumption and desired thermal comfort. The constraints impose lower and upper bounds for the supply AHU setpoints and for the room temperature and $\mathrm{RH}$.

Table 02: MPC results for 28 days between June and July using reduced physical models (Ph-MPC) and neural networks models (NN-MPC).

\begin{tabular}{|c|c|c|c|c|c|}
\cline { 2 - 6 } \multicolumn{1}{c|}{} & PID & $\lambda=1$ & $\lambda=100$ & $\lambda=1$ & $\lambda=100$ \\
\hline $\begin{array}{c}\text { Cooling } \\
\text { energy (kWh) }\end{array}$ & 14,227 & 4,648 & 15,244 & 5,286 & 15,063 \\
\hline $\begin{array}{c}\text { Heating } \\
\text { energy (kWh) }\end{array}$ & 9,234 & 7,726 & 13,051 & 6,759 & 11,942 \\
\hline $\begin{array}{c}\text { Mean temp. } \\
\left({ }^{\circ} \mathrm{C}\right)\end{array}$ & 21,47 & 23,77 & 23,51 & 22,54 & 22,6 \\
\hline $\begin{array}{c}\text { STD temp. } \\
\left({ }^{\circ} \mathrm{C}\right)\end{array}$ & 0,2 & 1,11 & 0,96 & 0,95 & 0,89 \\
\hline Mean RH (\%) & 52,31 & 53,98 & 45,09 & 57,23 & 48,57 \\
\hline STD RH (\%) & 3,7 & 4,49 & 2,81 & 6,92 & 2,82 \\
\hline
\end{tabular}

\section{The Planning Tool}

The planning tool (IndPT) developed in the INDIGO project (Rämä, 2018) aims to evaluate a planned district cooling system from energy efficiency, economics and emissions point of view. Other similar or related tools were identified and studied during the planning and development phase to avoid overlapping (Rämä and Klobut, 2018). The tool is an easy-to-use, open-source software developed in Python. At the heart of the tool is a model generator that produces a linear programming (LP) model representing a DC system based on user input. Numerous input parameters are predefined, but all can be modified through the graphical user interface (GUI) or by editing the text-based input data files. The input data includes both investment and operational costs, specific emissions of different sources and fuels, technology related parameters and many more.

The model is run to obtain data of cooling system's operation during a representative year. The results are used further on to calculate costs, revenues and emissions of the specified system. The economic and emissions calculations are carried out for a longer period of time; e.g. 20 years. This can be modified by the user.

Fig. 11 depicts the components available for system specification. Not all of them need to be included; just the specified items are used in LP model generation. For example, DC system can only include a compressionbased cooling unit with a connection to grid electricity and a DC storage.

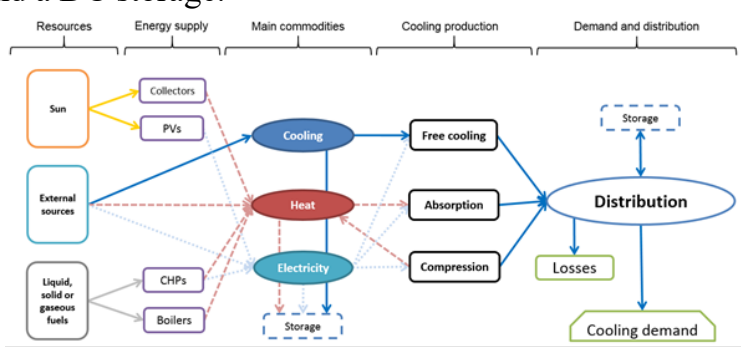

Figure 11: Components included in a DC system (based user input) used in generation of a LP model.

As a result, the user can see e.g. how the cooling is produced and what resources are used. Economic analysis provides a payback time for an investment and key performance indicators (KPIs), such as price of cooling supply (€/MWh). Emission analysis yields specific emissions of provided cooling $\left(\mathrm{kgCO}_{2} / \mathrm{MWh}\right)$, including also the embedded emissions of components specified in the system. The results are also compared to building-specific cooling systems to demonstrate the possible benefits of a DC system over such units. The same input data and other assumptions are used for both analyses.

\section{Conclusion}

Creation of dynamic models of a DC system and of the connected cooling demand plays an important role in the INDIGO project. The geometry of the buildings and the thermal properties of the structures, as well as some AHUs, the water buffer tank, some chillers and other components have been modelled. A detailed validation approach of the building envelope models was carried out and documented in this paper based on measurement taken on site. The integration of the building model with the AHUs models was tested. Through the validated models, improvements of the technical plants and of their management will be tested on the overall systems. Some proposed improvements of the control logics of the AHUs were already tested. They demonstrated that the MPC coupled with the NN model and with $\lambda=1$ yield savings of approx. $62 \%$ in the cooling energy and $26 \%$ in the heating energy compared to the PID controller, while maintaining the room temperature and RH close to the desired.

Furthermore, a high-level modelling tool has been developed for evaluation of a planned district cooling system from energy efficiency, economics and emissions point of view. This modelling approach, complementary with the detailed modelling presented in more detail in this paper, will also support feasibility study analysis and growth of District Cooling plants in EU.

In the context of detailed models and optimisation, the next step of the project will comprise a facility wide optimisation, including also generation and distribution systems optimisation. Once deployed, the same models will then be useful in testing new strategies and evaluating gaps between the expected performance and the real performance, in finding the causes of the possible discrepancies and in quantifying the energy and economic savings in comparison with the prior situation (before the implementation of INDIGO solutions).

\section{Acknowledgement}

INDIGO has received funding from European Union's Horizon 2020 research and innovation programme under grant agreement $\mathrm{n}^{\circ} 696098$.

Osakidetza is the public health service of the Basque country and it is the owner of the Basurto hospital, where Veolia-Giroa (partner of the project consortium) manages 
the DC systems. Osakidetza and Veolia-Giroa permit the use of the Basurto hospital as a pilot case.

\section{References}

Agencia vasca de meteorologia http://www.euskalmet.euskadi.eus

Blochwitz, T. (2012). Functional Mockup Interface 2.0: The Standard for Tool independent Exchange of Simulation Models. Proceedings of the 9th International Modelica Conference, 173-184. Retrieved from https:/trac.fmistandard.org/export/700/branches/public/docs/Modeli ca2012/ecp12076173_BlochwitzOtter.pdf

Costa, A. (2017). Development of Future EU District Cooling and Heating Network Solutions. Proceedings 1,974 .

EnergyPlus. Accessed December 2016. https://energyplus.net/

Febres, J, Sterling, R., and Keane, M. (2015). Automated calibration of Air Handling Unit models using a modified Preisach model. Proceedings of BS2015: 14th Conference of International Building Performance Simulation Association, 1547-1554. Retrieved from http://www.ibpsa.org/proceedings/BS2015/p2345.pdf

Febres, J., (2017). District Cooling Open Source Library (DCOL). Software.

FMU export of EnergyPlus http://simulationresearch.lbl.gov/fmu/EnergyPlus/exp ort/index.html

Hoyo Arce, I. (2017). Models for fast modelling of district heating and cooling networks. Renewable and Sustainable Energy Reviews.

Klobut, K. (2016). ICT technologies for energy efficient buildings and districts. 41st IAHS World Congress.

Loureiro, T. (2018). District Energy Systems: A Collaborative Exchange of Results on Planning, Operation and Modelling for Energy Efficiency. MDPI AG Proceedings, 2, 1127.

Modelica. Accessed December 2016. https://www.modelica.org

Nouidui, T.S.; Wetter, M.; Zuo, W. (2014). Functional mock-up unit for co-simulation import in EnergyPlus, Journal of Building Performance Simulation, 7(3): 192-202.

DOI: http://dx.doi.org/10.1080/19401493.2013.808265

Passerini, F. (2017)., Energy efficiency facets: innovative district cooling systems. Entrepreneurship and Sustainability Issues. V 4, No. 3.

Passerini, F. (2018). Integrated Energy Modelling to Support District Cooling Optimisation: Methodological Approach. Proceedings BSA 2017, 325. 2018.

Perfido D. (2017). Towards sustainable water networks: Automated fault detection and diagnosis,
Entrepreneurship and Sustainability Issues, 2017 DOI: DOI: 10.9770/jesi.2017.4.3S(9).

Rämä, M., and Klobut, K. (2018). Tools for Planning Energy Efficient District Systems. MDPI AG Proceedings, 2, 1132. 2018.

Rämä, M. (2018). INDIGO Planning Tool. Software.

Wetter, M.; Wangda, Z.; Nouidui, T.S.; Pang, X. (2014). Modelica Buildings library, Journal of Building Performance Simulation, 7(4): 253-270. DOI: http://dx.doi.org/10.1080/19401493.2013.765506

Wetter, M., Fuchs, M., Grozman, P. (2015). IEA EBC Annex 60 Modelica Library - An international collaboration to develop a free open-source model library for buildings and community energy systems. Proceedings of BS2015: 14th Conference of International Building Performance Simulation Association, 395-402. Retrieved from http://www.iea-annex60.org/downloads/p2414.pdf 